\title{
POSIBILIDAD DE UNA REFLEXIÓN ESTÉTICA A PARTIR DE JEAN PAUL SARTRE
}

\author{
Witton Becerra Mayorga* \\ Universidad Santo Tomás \\ Uno de los principales motivos de la creación artística es indudablemente \\ la necesidad de sentirnos esenciales en relación con el mundo. \\ Jean Paul Sartre \\ ¿Qué es la literatura?
}

"No gusto ni creo en las obras literarias de
filósofos como Sartre o Rousseau", menta-
ba Angelo Papacchini en el panel final del $X$
Congreso internacional de filosofía latinoa-
mericana. No sé cuál es el motivo de su dis-
tanciamiento con respecto a las obras litera-
rias de estos dos grandes de la filosofía y,
por supuesto, de las letras. Por el lado de
Rousseau, le diría que no he encontrado has-
ta el momento una obra literaria con todas
las implicaciones estéticas que aborde el pro-
blema de la educación como El Emilio, y que,
además, no es posible negar el romanticis-
mo que aflora en las obras de este autor. Por el lado de Sartre, bastaría con mentar su magnífica obra dramática y, por supuesto, una novela que tiene talante filosófico, pero que estoy convencido, implica un acercamiento estético: La náusea.

Hablar de Sartre es hablar del hombre, del filósofo y, por supuesto, del escritor ${ }^{1}$, aquel que se dio el lujo de rechazar el premio Nobel de Literatura en 1964 explicando que si lo aceptaba comprometería su integridad como escritor, integridad a la cual no renunció. Es por eso, tal vez, que no es del gusto de muchos y que haya sido acusado de polémico.

\footnotetext{
Estudiante de séptimo semestre, Facultad de Filosofía, Universidad Santo Tomás, Bogotá.

1 Cf. HERRERA RESTREPO, Daniel. Sartre: una libertad situada. En: Cuadernos de filosofía latinoamericana, No. 50-51, 1992, pp. 47-67.
} 
Acercarnos a Sartre y a su obra implica verdaderamente una experiencia estética, por supuesto de sus obras dramáticas y su literatura: La náusea, A puerta cerrada, Las moscas, La puta respetuosa, Los caminos de la libertad, Los secuestrados de Altona, Las palabras e, inclusive, el texto escrito con motivo de la muerte de su gran amigo Merleau Ponty, el cual contiene una dosis de magnífica prosa. Por eso, considero que Sartre puede ser ejemplo del acercamiento entre la filosofía, el arte y la literatura, motivo de reflexión en el pasado congreso. Por el lado de la filosofía, nos encontramos con Hegel, Marx, Heidegger y Husserl como motivadores de su pensamiento filosófico. Para conocer la filosofía sartreana tenemos que acudir a obras como El ser y la nada (1943) o La crítica de la razón dialéctica (1960).

Lo que importa aquí es elucidar los caminos que nos conducen a presenciar un acercamiento entre la filosofía y la literatura en Sartre y, por qué no, entre filosofía y arte, si entendemos al teatro como una expresión artística. Es claro que en Sartre se vislumbra claramente este acercamiento; empero, surge un interrogante, a saber, si la literatura y el arte dramático surgen en él como una vulgarización de su filosofía, o si por el contrario, hay que entender su filosofía primero, para entender luego su literatura y su teatro. Es un movimiento de doble vía que podría articularse si afirmamos que su obra filosófica es completamente autónoma, y la literatura y el teatro surgen desde esas concepciones filosóficas. El compendio filosófico de Sartre parece ser muy vasto si nos acercamos a una obra de las magnitudes de El ser $y$ la nada. Entonces, es necesario exponer de manera un poco más simplista lo que significan las concepciones morales y ontológicas expuestas por el autor. Esto es lo que se ha denominado como el "teatro de situación". Sartre expone su filosofía con argumentos plenamente filosóficos, pero para ser consecuente con su pensamiento opta por mostrar eso que conocemos como el ser-situado. Considero que lo más pertinente que pudo hacer nuestro autor fue descifrar la existencia humana por medio de las situaciones concretas en las que se dan las posibilidades de la existencia, difíciles de mostrar en el discurso radicalmente filosófico.

Este enfoque, que relaciona la filosofía con la vida, la literatura y la acción política, causó mucho interés en su momento porque quizá instaba a la posibilidad de relacionar los diversos discursos sobre aspectos que definían a la sociedad en que le tocó vivir. No creo que la propuesta sartreana expuesta en su filosofía y su literatura pueda definirse como interdisciplinar, ni que hablar de filosofía, arte y literatura se defina de esta manera, sencillamente porque no creo en los clichés que se nos imponen por simple discurrir vago y heterónomo. Muy bien lo dijo Eduardo Kronfly en el mismo panel, cuando se refería al diálogo "inter y transdiciplinar" entre filosofía, arte y literatura desde la perspectiva latinoamericana. “ ¿No es mejor hablar de diálogo entre culturas? ¿Entre modos de ser? ¿Entre modos de discurrir?”.

Por mi parte, pienso que Sartre nunca se propuso erigir su obra como algo inter-7 disciplinar, pues considero que él también detestaba los clichés que se ponen en boga como caprichos intelectuales. La obra sartreana es más que eso, es una muestra clara que define un modo de ser desde la filosofía, desde el arte y desde la literatura, que convergen en una visión única del hombre y del mundo: el existencialismo.

Concomitantemente, parangonando una de las implicaciones intelectuales expuestas por Sartre, es posible definir la estética como la posibilidad que tiene el hombre de comprender su existencia a través de la experiencia 
que devela algo de lo más íntegro de nuestra humanidad, la sensibilidad. La estética, pues, es una forma de darle sentido a nuestra existencia, y es posible percatarnos de que desde Sartre se puede entender como una de las instancias de ese sentido. La intencionalidad de la conciencia estará supeditada a darle sentido a la existencia, y la creación artística será un medio por el cual valoramos lo que significa ser hombre.

Cada una de nuestras percepciones va acompañada de la conciencia de que la realidad humana es "reveladora”, es decir, de que "hay” ser gracias a ella o, mejor aún, que el hombre es el medio por el que las cosas se manifiestan ${ }^{2}$; es nuestra presencia en el mundo lo que multiplica las relaciones; somos nosotros los que ponemos en relación este árbol con ese trozo de cielo; gracias a nosotros, esa estrella, muerta hace milenios, ese cuarto de luna y ese río se revelan en la unidad de un paisaje, es la velocidad de nuestro automóvil o nuestro avión lo que organiza las grandes masas terrestres; con cada uno de nuestros actos, el mundo nos revela un rostro nuevo. Pero, si sabemos que somos los detectores del ser, sabemos también que no somos sus productores. Si le volvemos la espalda, ese paisaje quedará sumido en su permanencia oscura. Quedará sumido por los menos; no hay nadie tan loco que crea que el paisaje se reducirá a la nada. Seremos nosotros los que nos reduciremos a la nada y la tierra continuará en su letargo hasta que otra conciencia venga a despertarla. De este modo, a nuestra certidumbre interior de ser "reveladores" se une la de ser inesenciales en relación con la cosa revelada.

Uno de los principales motivos de la creación artística es indudablemente la necesidad de sentirnos esenciales en relación con el mundo"3.

El mundo se nos da tal y como aparece, las cosas están llenas de ser; la conciencia simplemente es la develadora de ese ser que le permite a la vez ser ella como conciencia de algo. La conciencia intencional está situada, y explicitar esto es el papel de todo escritor, de todo artista, pues se cumplirá con la misión utópica de la literatura y el arte como la expresión de una conciencia, de la conciencia de ser, de estar situados. Es ese el camino que se emprende desde toda experiencia estética, para descubrirnos más humanos, y en ese humanizarnos descubrir el sentido de la existencia, pues ese es el rumbo de nuestra conciencia, posicionarnos y descubrir nuestra esencialidad en el mundo, pues estamos arrojados, y ese ser arrojados motiva el descubrimiento de nuestra relación con las cosas.

Establecer la correlación hombre-mundo es la misión del poeta, del escritor, del artista y, por supuesto, del filósofo. La experiencia estética sublima nuestra condición de hombres, y en esa búsqueda de sentido de nuestra existencia, la prosa, la poesía y el arte nos acercan al mundo, al ser de las cosas, a la vida y a la muerte. "Si los dioses se habían sacrificado a fin de que el mundo y la humanidad existiesen, entonces con más razón la

2 La analítica existencial ha llevado a Heidegger a reconocer la realidad humana como óntico-ontológica, precisamente por el hecho de que es por medio de la realidad humana que el ser se devela. La realidad humana es óntico-ontológica porque trasciende por medio de las estructuras de la conciencia el mundo, las cosas. De esta manera, es posible explicar la transfenomenalidad del fenómeno, y qué mejor que la experiencia estética para dar razones en favor de la subjetividad. Cf. SARTRE, Jean Paul. El ser y la nada. Barcelona: Altaya, 1993, p. 18.

3 SARTRE, Jean Paul. ¿Qué es la literatura? En: Obras completas. Vol. II. Buenos Aires: Losada, p. 1005. 
humanidad está obligada a arrojarse, de ser necesario, en las grandes hogueras de la vida y de la muerte" 4 .

Esto es pues lo que se propone Sartre al situar su reflexión filosófica en el teatro y en la literatura. Nos encontramos con un buen plato de aplicaciones estéticas a la reflexión filosófica. Pero el anclaje artístico y dramático como el situar de una reflexión filosófica no sólo es necesario sino deleitoso. Sartre define así la ficción, como la aventura, la aventura del sentido de la existencia, y el mismo Roquetin de La náusea descubre que sería mejor escribir ficción que dedicarse a redactar la historia del Marqués de Rollebon. No comparto la posición de Carlos Ramírez cuando afirma que "el único asidero de una existencia vacía - Roquetin- es dedicarse a escribir un libro. Es decir, la tentación estética" ${ }^{5}$. No es que escribir el libro no configure una experiencia estética, sino que el libro al que se refiere Ramírez -sobre la vida del Marqués de Rollebon- no responde a una experiencia estética sino al deseo de escribir una historia. Además, al finalizar la novela, Roquetin se arrepiente del tiempo que dedicó a escribir sobre el Marqués, y postulando la teoría de la ficción como aventura, afirma que sería mejor escribir ficción porque le daría más sentido a su existencia, lo que no había logrado con su intento de escribir la historia de Rollebon. Nos situamos, pues, en La náusea como obra capital para nuestro interés.

Pensar la existencia de un hombre solitario y arrojado en el mundo puede ser objeto de una reflexión, pero es ahí donde vemos resquebrajada la radicalidad conceptual de la filosofía. Es necesario escribir una novela con un protagonista y develar por medio de la prosa, de un diario, una reflexión sobre nuestra condición humana. Acercarnos a La náusea como principio esencial constituye una proximidad con la experiencia estética porque no estamos ante un discurso radicalmente conceptual, sino ante una prosa que surge de la intimidad de un escritor, Sartre.

Yo, por mi parte, soy de los que piensan que pensando somos mendigos pero creando somos dioses y casi diría que lamento la evolución posterior de Sartre (soy novelista, no puedo evitarlo). Creo que su ficción se enriquecía con todas esas contradicciones que luego lastraron su filosofía. Y que con "La náusea” había encontrado un medio perfecto para plasmar su esquizofrénico pensamiento con una contundencia poética apabullante, algo que a mi juicio falta en su filosofía 6 .

En La náusea nos encontramos con el ejemplo más claro que a mi consideración toca la relación entre la filosofía y la literatura, entendida ésta también como arte. Las implicaciones en la novela son siempre de talante filosófico, pero con una buena dosis de contundencia poética que describe, muestra y acciona la existencia de Roquetin como un arquetipo de pensamiento. Pensamiento que se ve reflejado en las descripciones de los lugares, las "personas", y la vida diaria que es necesario escribir, con las mayores

\footnotetext{
FUENTES, Carlos. El espejo enterrado. México: Fondo de Cultura Económica, p. 101.

Cf. RAMÍREZ AÍSSA, Carlos. Literatura contemporánea. Bogotá: El Búho, 1998, p. 90.

MAÑA, José Ángel. Prólogo a La Náusea. Madrid: El Mundo, p. 1.

Entendemos como tesis central de La náusea: "La náusea surge del encuentro con los otros y con las cosas, pues estas están repletas de ser”. Es por esta razón que es preciso aclarar que Roquetin es un hombre solo que no interacciona con los otros. Ese es el gran dilema de la novela, "forjar una esencia a partir de lo que es la existencia de un hombre en particular”. Cabe también aclarar el vuelco que da el pensamiento de Sartre y sus implicaciones en la concepción de la náusea. La náusea surge del encuentro con el otro y con lo otro, pero es la sociedad moderna la que la ha impuesto y no el encuentro particular entre los sujetos.
} 
sutilezas, pues la descripción de la esencia de un hombre ${ }^{8}$ se teje de manera artística por medio de la escritura.

Un diario es lo más íntimo del ser humano, y es de lo íntimo de donde surge la sensibilidad, la experiencia estética. No es posible imaginar un diario redactado con categorías estrictamente filosóficas. Recordemos que este lenguaje es abstracto y, en cuanto tal, no expresa la riqueza de la realidad concreta. Aunque La náusea pueda definirse como una novela de talante filosófico seguirá siendo una novela, con las implicaciones que este género posee. Sartre "es de los adictos a la concepción antigua de la novela, para la cual es indispensable al menos un paisaje, un hombre y una pasión”.

Es por esto que la interacción —que yo más bien definiría como el diálogo entre la filosofía y la literatura, entre la filosofía y el arte dramático (como es el caso del teatro de situación) — es de radical importancia para determinar una visión sartreana de la experiencia estética.

La misma novela a la que nos referimos aquí, se presenta como un discurso de la experiencia estética, teniendo como base la ficción como “aventura”.

He pensado lo siguiente: para que el suceso más trivial se convierta en aventura, es necesario y suficiente contarlo. Esto es lo que engaña a la gente, el hombre es siempre un narrador de historias; vive rodeado de sus historias y de las ajenas, ve a través de ellas todo lo que sucede, y trata de vivir su vida como si la contara.

Pero hay que escoger: o vivir o contar ${ }^{10}$.

Vivir sería el papel del Sartre dedicado a la filosofía, contar el papel del Sartre escritor y dramaturgo. Parece que se complica la cuestión, pero si entendemos que estamos arrojados y que tenemos que elegir, es posible que nuestras inclinaciones, y las del mismo Sartre, den origen a discursos diferentes. De manera tal que la expresión literaria surge como una pulsión del sujeto, como una motivación desgajada de la sensibilidad, como algo inesperado que motiva a escribir de corrido, sin pensar, sin meditar, para dar paso a lo más íntimo del hombre y expresarlo en la narración, en la poesía. Pero dentro de este fluir de la palabra, de la escritura, no se es ajeno a dejar la concepción del mundo, del hombre, de la vida, que se tiene. Es allí donde se inserta la filosofía en la expresión literaria y artística según sea el caso. En la literatura hay que pensar de corrido; de otro modo, es preciso desconfiar de la literatura. Nos dice Roquetin: "No necesito hacer frases. Escribo, para poner en claro ciertas circunstancias. Desconfiar de la literatura. Hay que escribirlo todo al correr de la pluma, sin buscar palabras, ${ }^{11}$ ” porque jamás se encontrarán si se está motivado a una experiencia estética.

La ficción, como componente estético, es aventura, aventura de escribir, de comprender que el ser se devela también en la experiencia estética. Y dice el Autodidacto: "Se-

Cf. con el estudio de Alfredo Gómez Muller “La biografie comme genre philosophique: Jean-Paul Sartre”. En: CAPELLE, Ph. (ed.). Subjectivité et trascendance. París: Cerf, 1999, p. 37 ss. Traducción al castellano en: FORNET-BETANCOURT, R., ed. Diskurs und Leidenschaft. Aachen, 1996.

8 Es preciso aclarar que la tradición fenomenológica a la que se adscribe Sartre entiende por esencia el sentido, el eidos de la existencia, separándose así de la antigua concepción aristotélico-tomista de esencia.

9 RAMÍREZ AÍSSA, Carlos. Op. Cit., p. 91.

10 SARTRE, Jean Paul. La náusea. Op. Cit., p. 53.

11 Ibíd., p. 20. 
ñor, creo que la aventura puede definirse así: un acontecimiento que sale de lo ordinario sin ser forzosamente extraordinario. Se habla de magia de las aventuras"12. La magia que se puede enarbolar en los momentos cotidianos de la existencia humana y que es preciso registrar con la pluma; la del escritor, la del literato, la del esteta. Ese es el caso de Sartre, aunque algunos, con razones de peso, afirmen la falta de estilo en el escritor $^{13}$. Sin embargo, cabe postular la preponderancia que Sartre da al arte de escribir, aunque lo acusen de falto de estilo. Esto se puede explicar: Sartre es un hombre de su tiempo; quizá es esta la razón por la que registra su momento histórico de la manera que lo hace, pero esto lo motiva a establecer una correlación hombre-mundo por medio de la experiencia estética y de la agudeza de una pluma "situada", en el sentido sartreano más lato.

¿Cuál es la exhortación que nos hace Sartre por medio de su literatura? “¿Qué es escribir? ¿Por qué se escribe? ¿Para quién? En realidad parece que nadie se ha formulado estas preguntas"14. Por esto, la literatura se convierte, en este y otros casos, en una utopía; ausculta las tramas de las experiencias humanas más grandes, nobles y diversas.

La literatura surge como defensa de la subjetividad ${ }^{15}$; por eso se escribe y se escribe, precisamente para soliviantar el papel del hombre en el mundo, el valor de su existencia y su libertad. No es más, se escribe porque es para el hombre que se escribe, es por el hombre que se escribe y es el hombre quien escribe. Se devela por medio de la escritura lo más íntimo del ser del hombre, su capacidad para crear, para darle sentido a su existencia. La prosa surge como un imperio de los signos, nos habla nuestro autor, $\mathrm{y}$, como diría Valéry, "la palabra pasa a través de nuestra mirada como el sol a través del cristal”.

De manera tal, que podemos dedicarnos con seguridad a esa voluptuosidad moderada que procuran, como todos saben, las obras de arte. Tal es, pues, la literatura "verdadera", "pura": una subjetividad que se entrega con la forma de lo objetivo, un discurso tan curiosamente dispuesto que equivale a un silencio, un pensamiento que se discute a sí mismo, una Razón que no es más que la máscara de la sinrazón, un eterno que nos da a entender que no es más que un momento de la Historia, un momento histórico que por las interioridades que revela, remite de pronto al hombre eterno, una enseñanza perpetua, pero que se efectúa contra las voluntades expresas de los que enseñan” ${ }^{16}$.

Sartre muestra que el arte y la literatura, como expresión de un pensamiento, tienen el derecho a levantarse, pues es el derecho que nos hemos ganado por la condena de nuestra libertad infinita ${ }^{17}$. Se cumple así la función utópica de la literatura y el arte. Como en épocas de Cervantes, de Rabelais, de Boccaccio, del Lazarillo de Tormes, de Rimbaud, de Baudelaire, de los místicos.

Hasta el momento me he referido a las posibles relaciones entre la filosofía y la literatura sartreanas. ¿Qué ha pasado con el teatro,

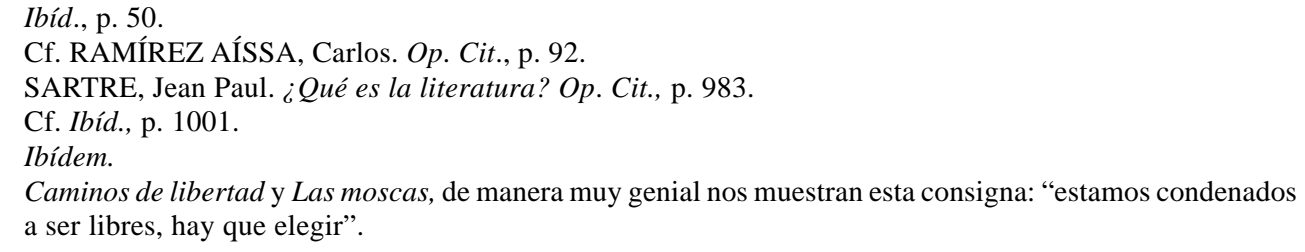


pues parecía ser uno de mis argumentos más fuertes? Considero que el teatro en este caso es más autónomo, por lo cual la referencia podría tomarse de manera más sutil. Claro está que hay muchas posibilidades de sentido que aquí no tocaré.

La obra dramática en Sartre es el vivo ejemplo de la necesidad de exponer por medios diferentes un discurso filosófico. Lo vemos en Las moscas, A puerta cerrada, La puta respetuosa, de manera más concreta. Los temas de la libertad, la existencia del prójimo y la dignidad humana son tocados aquí con un contexto determinado, la época de la posguerra. En este contexto es pertinente mostrar lo que Iris Zabala denomina el discurso$a o^{18}$ para confirmar que el teatro sartreano lo quebranta, pues en estas circunstancias no es posible creer en la autoridad ni en la "justicia”. Dejo aquí, para tratar en otro momento, el papel y la inclusión del otro en la literatura y el teatro de Jean Paul Sartre. Sólo cabe señalar que el performance de cualquier obra de teatro merece la dedicación estética del caso, argumento suficiente para recalcar el papel que se juega el arte en una obra de teatro con implicaciones filosóficas.
Parece ser que la filosofía, el arte y la literatura son discursos y formas que se complementan, que se sirven mutuamente, que se conjugan para, en el caso de Sartre, develar el sentido de la existencia. Pero ¿por qué es importante Sartre en este discurso? Porque es una muestra de la relación profunda entre filosofía, arte y literatura. La gloria de Sartre se debe a "las sinergias entre sus escritos de narrativa, filosofía y teatro" ${ }^{19}$. Y en esta discusión:

Cada cual tiene sus razones: para este el arte es un escape; para aquel, un modo de conquistar. Pero cabe huir a una ermita, a la locura, a la muerte y cabe conquistar con las armas -como la pluma. ¿Por qué precisamente escribir, hacer por escrito esas evasiones y esas conquistas? Es que, detrás de los diversos propósitos de los autores, hay una elección más profunda e inmediata, común a todos”20.

A saber, la de cumplir con la misión utópica de la literatura y del arte como expresiones del pensamiento filosófico.

18 Zabala sienta las bases del discurso-amo desde el desenmascaramiento que propone Lacan. El marco teórico no nos interesa, lo que importa es la categoría de discurso-amo para señalar la exclusión y la desigualdad que en el teatro sartreano son muy comunes. Por eso "lo soliviantador del arte y la literatura". Cf. ZABALA, Iris. Sísifo, América y la repetición. En: X Congreso internacional de filosofía latinoamericana. Bogotá: Universidad Santo Tomás, 2004, pp. 45-62.

19 RAMÍREZ AÍSSA, Carlos. Op. Cit., p. 92.

20 SARTRE, Jean Paul. ¿Qué es la literatura? Op. Cit., p. 1005. 